\title{
Interação Mãe-Bebê: Um Processo de Descobertas
}

\author{
Dorian Mônica Arpini \\ Edinara Zanatta \\ Rafaela Quintana Marchesan \\ Suane Pastoriza Faraj* \\ Carolina Sarzi Ledur
}

Universidade Federal de Santa Maria, Santa Maria, RS, Brasil

Caroline de Oliveira Mozzaquatro

Escola de Saúde Pública, Santa Maria, RS, Brasil

\begin{abstract}
RESUMO
Considerando a importância que as primeiras experiências têm para a constituição psíquica e tendo como referência que elas ocorrem a partir das relações parentais, este estudo objetivou compreender os aspectos que indiquem saúde e bem-estar na relação mãe-bebê, tendo como foco os momentos de amamentação, choro, comunicação e interação entre a díade. Foram realizadas observações e uma entrevista com as mães. Os resultados foram obtidos através da análise de conteúdo e apontam a presença dos indicadores do instrumento IRDIs na relação entre a díade, evidenciando um saber das mães sobre seus filhos. As considerações finais destacam a importância da relação mãe-bebê e sugerem a inclusão dos Indicadores Clínicos de Risco ao Desenvolvimento Infantil em serviços de atenção primária em saúde.

Palavras-chave: relações mãe-filho; desenvolvimento infantil; relações familiares; atenção à saúde; psicologia da criança.
\end{abstract}

\begin{abstract}
Mother-Infant Interaction: a Process of Discoveries

Considering the importance of the first experiences to the psychological constitution and that such constitution is based on parental relationships, this study aimed to comprehend the aspects that indicate health and well-being in the mother-baby relationship, focusing on the moments of breastfeeding, cry, communication and interaction of the dyad. The study was grounded on observation and an interview with the mothers. Results emerged from content analysis and highlight the presence of indicators of the Child Development Risks Index (IRDIs) in the relationship of the dyad, evidencing mothers hold knowledge about their babies. Final considerations emphasize the importance of the mother-baby relationship and suggest the inclusion of Clinical Indicators of Risk regarding Child Development in services of primary health care.
\end{abstract}

Keywords: mother-child relations; child development; family relations; health care; child psychology.

Considerando a importância que as primeiras experiências têm para a constituição psíquica e tendo como referência que elas ocorrem a partir das relações parentais, debruçar-se sobre a forma como esses cuidados e essas relações se constroem tem sido uma tarefa que se impõe aqueles que se ocupam da infância, em especial dos cuidados com bebês (Pierotti, Levy, \&
Zornig, 2010; Vitorello, 2011). Baseados no relatório de 2001 da Organização Mundial da Saúde e em outros estudos, Kupfer et al. (2009) expõe que os transtornos mentais são comuns na infância e adolescência, porém o diagnóstico e o tratamento são ainda insuficientes, o que acaba deixando um grande número de crianças sem a devida assistência. Em função dessa

* Endereço para correspondência: Suane Pastoriza Faraj - suanef@yahoo.com.br 
defasagem no atendimento foram pensados Indicadores Clínicos de Risco ao Desenvolvimento Infantil, chamada de pesquisa IRDI, com o objetivo de detectar, ainda na primeira infância, problemas relativos ao desenvolvimento infantil, com aplicação significativa na saúde mental. Tal pesquisa foi realizada pelo GNP - um grupo de psicanalistas reunidos pelo Ministério da Saúde em 1999 - no período entre 2000 e 2008, e culminou com o desenvolvimento de um instrumento composto por 31 indicadores clínicos de risco psíquico ou de problemas de desenvolvimento infantil observáveis nos primeiros 18 meses de vida de uma criança (Kupfer et al., 2009).

Na referida pesquisa privilegiou-se a articulação entre desenvolvimento e sujeito psíquico, sem desconsiderar os processos maturativos de ordem neurológica e genética - estes geralmente alvos das pesquisas sobre desenvolvimento. Por sujeito psíquico entendese que o sujeito se constrói desde o início da vida, através do campo social que é anterior a ele, e que contém a história de um povo, da família e do desejo dos pais. Os encontros e intercorrências que ocorrem na trajetória singular de cada um também o construirão enquanto sujeito psíquico, e assim ele construirá um lugar único para ele próprio a partir dessa construção (Kupfer et al., 2009). Essa compreensão faz com que os responsáveis por seus cuidados e por sua evolução tenham um papel primordial, já que o lugar do sujeito dependerá das ações gerais que o cuidador irá realizar na primeira infância. Como exposto acima, na construção dos indicadores da pesquisa IRDI os aspectos ligados ao sujeito psíquico foram privilegiados, de modo que a presença dos indicadores na criança indica que ela está em desenvolvimento saudável, e a ausência dos IRDIs é que indica riscos ao desenvolvimento. Dessa forma, os indicadores foram concebidos de maneira positiva, de modo que quando incluídos em um protocolo de consultas regulares de pediatras, eles verão a saúde da criança, desfocando o olhar sobre a doença (Kupfer et al., 2009).

Ademais, caso haja a ausência de algum IRDI, o pediatra ou profissional de saúde pode suspeitar que algo não vai bem, porém isso não o levará a fechar um diagnóstico definitivo e definidor. Este diagnóstico pode ser desastroso e selar um destino quando ainda há possibilidades de modificações, já que conforme Kupfer et al. (2009), seguindo os pressupostos de Winnicott, há plasticidade na construção singular do sujeito, e as intercorrências que ocorrem não deixam que se selem diagnósticos. Considerando os pressu- postos dos IRDIs, optamos por priorizar as referências de Winnicott (1987/1999), Bowlby (1988/1989) e Spitz (1965/1998), em função da relevância desses autores para a compreensão do tema e de sua sintonia com os aspectos do protocolo, sem, contudo, desconsiderar a importância de outros autores em relação à temática.

Para Winnicott (1987/1999) o desenvolvimento da saúde mental do indivíduo está sendo construído pela mãe, que proporciona um ambiente facilitador para o bebê, assentando as bases da saúde mental do filho, sem que ela saiba disso. O ambiente facilitador proporciona que os processos evolutivos e as interações do bebê com o meio desenvolvam-se de acordo com o seu padrão hereditário. Assim, de acordo com Winnicott (1982/1983), toda criança tem um potencial herdado no sentido do crescimento e do desenvolvimento, o que faz com que as condições favoráveis ou desfavoráveis não determinem o potencial do lactente. Contudo esse potencial não é suficiente, e não garante um desenvolvimento saudável, já que o bebê só se torna um bebê se estiver envolvido ao cuidado materno, visto que é totalmente dependente, e sem essa condição não pode começar a vir a ser.

A criança começa a ser a partir de um cuidado satisfatório, proporcionado por uma mãe que provém um ambiente suficientemente bom. Esse cuidado materno, chamado pelo autor de Preocupação Materna Primária, fornece um contexto para que "a constituição da criança comece a se manifestar, para que as tendências ao desenvolvimento comecem a desdobrar-se, e para que o bebê comece a experimentar movimentos espontâneos e se torne dono das sensações correspondentes a essa etapa inicial da vida" (Winnicott, 1958/2000, p. 403). Para isso, será necessária uma identificação da mãe com o bebê, que é consciente, mas também é profundamente inconsciente (Winnicott, 1958/2000).

Assim, é o estado de identificação com o bebê que as tornam capazes de se colocarem no lugar dos filhos, indo ao encontro das necessidades básicas destes, de uma forma que não pode ser imitada e nem ensinada (Winnicott, 1987/1999). Nesse período a mãe preocupa-se com o seu bebê e em atender e adaptar-se às necessidades dele, excluindo de forma temporária qualquer outro interesse que poderia vir a ter. Porém, não são todas as mães que conseguem identificar-se com o bebê nessa fase inicial do desenvolvimento. 
A linha da vida de uma criança é muito pouco perturbada por reações a intrusões quando a mãe é suficientemente boa, e consegue uma adaptação sensível às necessidades do bebê, colocando-se no lugar deste e, assim, assenta as bases para o estabelecimento do ego. Dessa forma, "capacita o bebê a começar a existir, a ter experiências, a construir um ego pessoal, a dominar os instintos e a defrontar-se com todas as dificuldades inerentes à vida" (Winnicott, 1958/2000, p. 404). Quando os bebês são segurados e manipulados de forma satisfatória, adquirem confiança em um mundo amigável (Winnicott, 1987/1999), de modo que o termo segurar é usado por Winnicott (1982/1983) também com o nome de holding, abarcando a ideia não apenas no sentido físico de segurar o bebê, mas também a provisão ambiental.

O bebê tem o comportamento de apego, segundo Bowlby (1969/2002), para garantir a proximidade com a mãe, sendo um comportamento com fins de interação social. Para o autor, o bebê tem o aparato inato para responder a estímulos sociais, e os usa desde o início da vida, sendo que tais comportamentos são mais visíveis a partir dos seis meses de vida da criança. Porém, a partir dos três meses, a maioria dos bebês responde à mãe de um modo diferente se comparado à outras pessoas. Ele sorrirá e vocalizará quando vir à mãe, seguindo esta com os olhos, até que consiga manter proximidade com ela. Dessa, forma os bebês sentem amor pelas suas figuras de apego, ficando alegres com a chegada destas, e sentem-se seguros com a presença ou proximidade da figura principal de apego (Bowlby, 1969/2002).

Os meios de o bebê atrair a atenção da mãe e trazê-la para junto a si vão mudando conforme o bebê vai desenvolvendo seu aparato perceptual e físico. Inicialmente, o bebê recorre ao choro e à sucção, e com esta alia o movimento de agarrar a mãe. Para Winnicott (1987/1999), a amamentação é um cenário privilegiado dentro do repertório de cuidados maternos, pois é um elemento que facilita o exercício da função materna e possibilita a construção das primeiras relações objetais (Costa \& Locatelli, 2008; Cunnigham, Jelife, \& Jelife, 1991; Klein, 1952/1991). Assim, para além do leite, a amamentação permite trocas afetivas e constitui a comunicação entre a mãe e o bebê (Kruel \& Souza, 2014).

Outro aspecto que exerce importância na constituição do laço entre a díade é a fala que a mãe dirige ao bebê, chamada de manhês ou motherese, e que é importante para a construção de um sistema de comunicação entre ambos. Nesta modalidade de fala, as mães tendem a mudar o tom da voz, vocalizando sons tranquilizadores, aproximando-se a uma cantiga, de modo que a voz musicalizada da mãe é um ponto de referência para o surgimento do psiquismo do bebê (Scorsi \& Lyra, 2012). Caracteriza-se, além disso, por ser uma fala simplificada, na qual a mãe busca habilitar o bebê a participar da comunicação (Flores, Beltrami, \& Souza, 2011), sendo que a mãe, às vezes, assume a posição do bebê e expressa na sua fala o que ele poderia estar sentindo (Scorsi \& Lyra, 2012). Segundo Pierotti et al. (2010) o bebê se deixa seduzir pela dinâmica da fala materna, sendo fundamental a presença manifestada pela voz da mãe que lhe é endereçada.

A partir dessas experiências, o bebê começa a sorrir quando vê a mãe, e poucas semanas depois já consegue balbuciar algumas palavras para chamar a sua atenção. A presença continuada da mãe, através dos seus cuidados ao filho, possibilita o nascimento da sua subjetividade ou, em outras palavras, "são estes cuidados que humanizam o bebê" (Avellar, 2004, p. 16). Spitz (1965/1998) postula que as atitudes intencionais da mãe para o bebê, no primeiro ano de vida, serão decisivas e influenciarão no desenvolvimento de vários setores de sua personalidade. No decorrer das semanas, a busca de comunicação com a mãe, além de evidente, se torna cada vez mais dirigida, e o êxito fará com que ele repita a experiência, já que obtém prazer com o sucesso. Porém, quando as ações de busca de comunicação são frustradas regularmente pela mãe, logo o bebê desistirá dessa busca. Dessa forma, ações realizadas pelo bebê que a mãe sente como agradáveis são encorajadas, e serão facilitadas por ela, que terá uma influência direta no desenvolvimento do bebê através das suas preferências, e "seus afetos, seu prazer, suas próprias ações, conscientes ou inconscientes, facilitam inúmeras e várias ações do filho" (Spitz, 1965/1998, p. 12).

Nesse sentido, destaca-se a importância das relações iniciais entre mãe e bebê para a constituição do vínculo entre ambos e para o desenvolvimento infantil. Além disso, a inserção da psicologia no campo da atenção primária possibilita a ampliação do olhar acerca do desenvolvimento dos bebês, auxiliando na prevenção de doenças e promoção de saúde, posto que a saúde-doença é um fenômeno multideterminado, 
requisitando de um olhar que envolva vários saberes que, inter-relacionados, deem conta da complexidade de elementos e fatores que influenciam no desenvolvimento infantil. Ainda, o psicólogo inserido nesse contexto pode oferecer uma significativa contribuição a partir do entendimento contextualizado e integral do sujeito, da família e da comunidade (Arpini \& Santos, 2007; Böing \& Crepaldi, 2010).

Contudo, para que todos os aspectos aqui abordados sejam alcançados, salienta-se a importância do preparo dos profissionais que compõem as equipes nos serviços de atenção primária em saúde, no sentido de poder dar conta destes aspectos relacionais tão importantes, de modo que o profissional de psicologia parece ter uma tarefa primordial na área materno infantil. No entanto, por ainda ser considerado um especialista, nem sempre se encontra presente na atenção primária, local onde se inserem os profissionais generalistas (Böing \& Crepaldi, 2010). Assim, estudos dessa natureza podem se constituir numa possibilidade de evidenciar a importância da inclusão de profissionais da psicologia preparados para acolher e compreender as relações das mães e seus bebês.

Por fim, considerando os apontamentos acima destacados, este estudo objetivou compreender os aspectos que indiquem saúde e bem-estar na relação entre mãe e bebê, tendo como foco os momentos de amamentação, choro, comunicação e interação entre a díade. Tais aspectos encontram-se presentes no protocolo IRDIs.

\section{MÉTODO}

\section{Desenho do estudo}

O estudo foi realizado junto a uma unidade de atenção básica de uma cidade de porte médio do interior do Rio Grande do Sul, em um dos programas realizados no local, chamado Programa da Criança, no período de 2011 e 2012. Escolheu-se este programa em específico por ser realizado no referido local um trabalho de atendimento com crianças na faixa etária entre zero a dois anos, cobrindo o período inicial do desenvolvimento, o período de zero a oito meses incompletos, foco do estudo.

No referido programa, as consultas se dão em um tempo médio de meia hora para cada criança, onde estas são medidas e pesadas por profissionais da enfermagem que acompanham mês a mês a curva de crescimento, presente na Caderneta de Saúde da Criança que é disponibilizada pelo Ministério da Saúde. Observa-se, também, o estado vacinal, orientando as mães quanto aos prazos das vacinas para que os bebês estejam em dia com o seu calendário vacinal.

Além de constatar como está o desenvolvimento físico e motor das crianças, o Programa da Criança esclarece dúvidas e orienta as mães com relação ao desenvolvimento dos filhos, tanto nos aspectos físicos, realizado pela enfermagem, bem como nos aspectos psíquicos, a cargo da psicologia. Tal acompanhamento realizado pelo programa às díades é caracterizado por Arpini e Santos (2007) pela sua relevância para a manutenção da relação mãe-bebê - reassegurando, promovendo e estimulando os vínculos iniciais - visto que o olhar da equipe está direcionado para as sutilezas presentes nessa relação, que podem vir a ser negligenciadas pelas mães em função de sobrecarga e cansaço. Tendo isso em vista, as autoras indicam a possibilidade de a psicologia estar no campo da saúde pública, na promoção de saúde, com o seu trabalho para o cuidado concernente à construção dos laços afetivos.

\section{Descrição dos participantes}

Participaram desse estudo onze díades formadas por bebês, na faixa etária de zero a oito meses incompletos, e suas respectivas mães, que levavam seus filhos e os acompanhavam durante o atendimento realizado pela equipe do programa. Compreendeu-se essa faixa do desenvolvimento dos bebês por coincidir com os primeiros 13 indicadores da pesquisa IRDI proposta por Kupfer et al. (2009). Ademais, acreditase que essa fase inicial do desenvolvimento é crucial na vida de uma criança, já que alicerça as bases do desenvolvimento futuro, bem como expõem Winnicott (1958/2000) e Spitz (1965/1998). No momento do estudo, todas as mães estavam morando com o pai do bebê e a maioria delas dedicava-se prioritariamente aos cuidados da família e da casa.

No quadro abaixo, são apresentados alguns dados relativos aos bebês e suas mães. A idade dos bebês expressa no quadro corresponde ao momento da entrevista. 
Quadro 1

Dados dos Participantes

\begin{tabular}{|c|c|c|c|c|c|}
\hline Díade (D) & Idade do bebê & Sexo do bebê & Idade da mãe & $\mathbf{N}^{\circ}$ de filhos & Ocupação da mãe \\
\hline D1 & 5 meses & Feminino & 25 anos & 1 & Dona de casa \\
D2 & 6 meses & Feminino & 28 anos & 1 & Dona de casa \\
D3 & 6 meses & Feminino & 22 anos & 2 & Dona de casa \\
D4 & 5 meses & Masculino & 45 anos & 3 & Comerciante \\
D5 & 4 meses & Masculino & 25 anos & 2 & Dona de casa \\
D6 & 6 meses & Masculino & 38 anos & 3 & Dona de casa \\
D7 & 6 meses & Masculino & 37 anos & 4 & Dona de casa \\
D8 & 3 meses & Feminino & 22 anos & 2 & Vendedora \\
D9 & 4 meses & Masculino & 28 anos & 1 & Vendedora \\
D10 & 4 meses & Feminino & 29 anos & 4 & Dona de casa \\
D11 & 7 meses & Masculino & 21 anos & 2 & Dona de casa \\
\hline
\end{tabular}

\section{Instrumentos}

Durante a coleta de dados, foram realizadas três observações da relação mãe-bebê no momento em que o bebê estava sendo atendido no Programa da Criança, sendo que desde a primeira observação as mães já haviam aceitado participar da pesquisa. Delimitou-se esse período de observação a fim de ter uma visão mais ampla do desenvolvimento infantil e da relação mãe-bebê. Ademais, foi utilizado o instrumento proposto por Kupfer et al. (2009), os IRDIs, como guia no momento da observação.
A pesquisa IRDI separa no seu instrumento períodos de desenvolvimento de zero a quatro meses incompletos, quatro meses a oito meses incompletos, oito meses a doze meses incompletos e doze meses a dezoito meses. No presente trabalho, como já mencionado, foram observados treze dos indicadores da pesquisa IRDI, por estes compreenderem o período do desenvolvimento infantil que foi o foco de atenção deste estudo. Segue abaixo o quadro da pesquisa IRDI proposta por Kupfer et al. (2009), onde estão presentes os 13 indicadores que foram observados nos três encontros com a díade mãe-bebê.

\section{Quadro 2}

Indicadores Clínicos de Risco para Desenvolvimento Infantil e Respectivos Eixos Teóricos

\begin{tabular}{|c|l|}
\hline $\begin{array}{c}\text { Idade em } \\
\text { Meses }\end{array}$ & Indicadores \\
\hline $\begin{array}{c}\text { me a } 4 \\
\text { meses }\end{array}$ & $\begin{array}{l}\text { 1. Quando a criança chora ou grita, a mãe sabe o que ela quer. } \\
\text { 2. A mãe fala com a criança num estilo particularmente dirigido a ela (manhês). } \\
\text { 3. A criança reage ao manhês. } \\
\text { 4. A mãe propõe algo à criança e aguarda a sua reação. } \\
\text { 5. Há trocas de olhares entre acriança e a mãe. }\end{array}$ \\
\hline $\begin{array}{c}\text { 6. A criança começa a diferenciar o dia da noite. } \\
\text { 7. A criança utiliza sinais diferentes para expressar suas diferentes necessidades. }\end{array}$ \\
$\begin{array}{l}\text { 8. A criança solicita a mãe e faz um intervalo para aguardar sua resposta. } \\
\text { 9. A mãe fala com a criança dirigindo-lhe pequenas frases }\end{array}$ \\
$\begin{array}{l}\text { 10. A criança reage (sorri, vocaliza) quando a mãe ou outra pessoa está se dirigindo a ela. } \\
\text { incomplet. A criança procura ativamente o olhar da mãe. } \\
\text { 12. A mãe dá suporte às iniciativas da criança sem poupar-lhe o esforço. } \\
\text { 13. A criança pede a ajuda de outra pessoa sem ficar passiva. }\end{array}$ \\
\hline
\end{tabular}


Após a realização das observações foi agendada uma entrevista com as mães participantes da pesquisa na própria Unidade. As mães foram previamente avisadas que a entrevista se daria após a terceira observação. Foi dada a elas a possibilidade de escolherem realizá-la no mesmo dia da terceira observação ou agendá-la para outro dia. Assim, oito das onze mães optaram por fazer a entrevista logo após a consulta no programa, e três preferiram retornar em outro dia. Todas as entrevistas foram gravadas e realizadas em uma sala concedida pelo responsável da unidade, devidamente equipadas com cadeiras e uma mesa e onde se tinha total privacidade. Inicialmente foi apresentado às mães o termo de Consentimento Livre e Esclarecido, o qual foi lido e, posteriormente, assinado pelas participantes. Após esse momento inicial, procedeu-se à realização da entrevista propriamente dita.

A entrevista foi de caráter qualitativo, chamada de entrevista do tipo semiestruturada, seguindo como tópicos-guia: a gestação; as primeiras semanas; o choro; a amamentação e a interação mãe-bebê. Tal perspectiva segue os preceitos apontados por Gaskell (2002), autor que entende que esse tipo de entrevista fornece os dados básicos para a compreensão das relações que existem entre os atores sociais, e a situação em que eles se encontram, sendo possível chegar a uma compreensão detalhada das crenças, atitudes, valores e motivações das pessoas naquele contexto social específico.

\section{Análise dos dados}

Após a realização das entrevistas foi realizada a transcrição das mesmas e iniciou-se o procedimento de análise, tendo como base a proposta de Bardin (1977). Procedeu-se, inicialmente, à análise individual de cada díade considerando as observações, o protocolo IRDIs e a entrevista, momento no qual cada dupla foi objeto de análise e os aspectos referentes ao desenvolvimento foram avaliados. Após a análise de cada díade em separado, passou-se a um segundo momento que buscou a integração das díades participantes, momento no qual os aspectos que mais se fizeram presentes tanto nas observações quanto na fala das mães, decorrentes das entrevistas e de seus questionamentos durante as consultas, foram agrupados, constituindo as categorias aqui apresentadas: o saber sobre o filho; comunicação mãe-bebê; amamentação e a relação vista como gratificante pela mãe. Destaca-se, contudo, que como o estudo teve por base as observações e o protocolo IRDIs, já havia um direcionamento com relação ao processo de categorização, considerando que foram observados aspectos comuns e padronizados. Por fim, cabe informar que ao final de cada análise individual das díades se organizou um protocolo de devolução dos resultados para as mães, procedimento que já havia sido acordado desde o momento de inclusão das participantes no estudo. Nesta entrevista, foram apontados os aspectos observados, destacando os itens que constam no protocolo IRDIs. Destaca-se que esta entrevista se constituiu num momento importante e muito gratificante tanto para as mães quanto para as pesquisadoras. Com relação aos aspectos éticos, a pesquisa seguiu todos os procedimentos de acordo com a resolução 196 que regulamenta a pesquisa em seres humanos, sendo que a mesma foi submetida e aprovada pelo Comitê de Ética em Pesquisa da Instituição onde as pesquisadoras atuam, sob o registro 0077.0.243.000-11.

\section{RESULTADOS E DISCUSSÕES}

\section{0 saber sobre o filho}

No decorrer das entrevistas e observações das díades participantes desta pesquisa, pode-se se evidenciar o saber diferenciado que a mãe porta em relação ao seu bebê, na medida em que atribui e reconhece, no filho, necessidades, preferências, características, modos de agir e de se comunicar. A atribuição de algumas preferências aos bebês ocorreu, por exemplo, na medida em que as mães ressaltavam objetos e/ou atitudes que causavam prazer ou desprazer ao filho. $\mathrm{Na}$ díade 8 , por exemplo, a mãe referiu que a filha estava "faceira" no dia da entrevista, pois "adora sair". As díades 2 e 10, além disso, elegem a música como uma preferência do bebê, mencionando que ela faz com que o filho se anime ou se acalme, respectivamente.

[...] e ela adora música! E agora às vezes ela tá um pouquinho impertinente, um pouquinho irritada, ai eu coloco uma música mais suave, pego no colo, embalo, embalo, ou às vezes digo "agora nós vamos dançar, a mãe não pode ficar contigo todo tempo", aí fico com ela, quando vê ela dorme, e é bem tranquilinha. (D10)

Além disso, estava presente, no discurso das mães, o reconhecimento de características tidas como próprias ao filho, a exemplo da distinção do bebê em uma criança "calma" ou "ativa/agitada", conforme mencio- 
nado por grande parte das entrevistadas: "Sim, ela tá, ela é muito ativa, ela é muito ativa, ela tá no carrinho dela, ela tem os brinquedinho dela de pega na mão, ela bate, ela grita, sabe, ela tá sempre, olha, tá sempre fazendo as dela" (D2) e, ainda, "Tanto que eu pedi pra Deus, Deus me deu bem calminho, bem tranqüilo. Não é agitado, não é nervoso, chorão, só chora pra mama" (D9).

No que se refere a esta diferenciação do choro do bebê, pela mãe, este foi um aspecto bastante explorado no decorrer da pesquisa, na medida em que nos permite visualizar a identificação da mãe com o bebê. Para algumas das mães entrevistadas, essa compreensão e diferenciação dos sinais do bebê - do choro, em especial - foi se constituindo progressivamente. $\mathrm{Na}$ díade 1, por exemplo, a mãe expressa certa confusão nesse início do discernimento do choro do bebê, relatando que, posteriormente, adquiriu maior domínio sobre a questão: "Ah, no início foi estranho, não sabia o que que era. Eu ficava angustiada, sabe! Não sei, o que será que tem? [...] agora eu sei como é que é, quando ta com fome, quando ta com dor". Essa confusão inicial deve-se ao fato de que, nas primeiras semanas, a díade se conhece muito pouco, não havendo o estabelecimento de um padrão de comunicação entre mãe e filho, podendo haver dificuldades na distinção dos sinais do bebê (Borsa, 2007).

Na medida em que o par mãe-filho passa a interagir, entretanto, o reconhecimento em relação às necessidades do bebê tende a se tornar mais especializado. Este tipo de saber da mãe, em relação ao filho, remete aos indicadores 1 e 7 do instrumento IRDI, e foi verificado em grande parte das díades entrevistadas, tendo em vista que as mães demonstraram grande domínio na decodificação dos diferentes sinais e necessidades do filho:

Agora eu já sei, vamos dizer assim, sabe quais os motivos que ela chora, o que que tem, né? [...] Não sei se pelo período que eu ainda tô com ela, então eu consigo saber tudo, desde a hora que acorda até a hora de dormir, então eu sei mais ou menos lidar com as situações dela, né? Tem dias que ela tá bem irritada, e eu já to sabendo melhor lidar com ela, né? [...] Primeiro eu dou mama, aí depois eu troco a fralda, se ela continua eи pego dou uma passeada, se não pára eu aperto o ouvidinho pra ver se dói alguma coisa. Geralmente é isso, ou espero alguma coisa assim, mas geralmente eu dou mama e troco fralda, é o básico do dia-a-dia. E pego um pouqui- nho no colo, que às vezes quer um pouquinho de atenção mesmo. (D8)

Entretanto, em uma das díades participantes da pesquisa, a díade 4, essa adaptação da mãe às necessidades do bebê demonstrou-se, em certa medida, prejudicada, tendo em vista que a mãe atribuía uma importância central ao seu trabalho, o que comprometia sua disponibilidade para com o bebê. Assim, a mãe demonstrava uma preocupação referente aos cuidados corporais e as necessidades físicas do bebê, mas havia pouca disponibilidade afetiva e lúdica para com ele.

A respeito, ainda, dessa sintonia existente entre a díade, Avellar (2004) refere que a mãe, a fim de cuidar de seu bebê, conjuga seu ritmo ao dele, constituindo uma "experiência de mutualidade". Para chegar neste ponto, a mãe já teria vivenciado o que é ser um bebê cuidado e, ainda, cuidou ou brincou de cuidar bebês. O bebê, por sua vez, está experienciando pela primeira vez o que é ser um bebê, prevalecendo, inicialmente, suas tendências inatas e herdadas.

Posteriormente, as experiências com a mãe passarão a ser experiências de presença e ausência, estas últimas na medida do suportável para o bebê, o que somente a mãe é capaz de perceber (Avellar, 2004). Sobre essas experiências de ausência com a mãe, este aspecto é abordado no indicador 8 do instrumento IRDI, sendo também explorado durante a entrevista com as mães, no momento em que foram questionadas sobre como é o momento de espera do bebê, quando este solicita a mãe. Em seu discurso, as mães demonstraram perceber como o filho sente e lida com essa ausência, referindo que esse momento de espera costuma ser difícil para o filho. Foi perceptível, entretanto, a dificuldade que as próprias mães, em algumas das díades, sentiam em proporcionar esse momento de espera e ausência para o bebê:

Não, ela quer naquela hora ali mesmo, as vez eu até brinco com ela, digo "espera um pouquinho", ela não, ahã, não gosta de espera, tem que se naquela hora, tem que para o que tá fazendo, tem que para. (D3)

[...] eu procuro não deixa, a vó disse que eu sou sem vergonha, eu não deixo ele esperando, eu corro lá alcançá se ele que alguma coisa, e o certo é vê se ele fica esperando um poquinho, dá um tempinho. (D6) 
A fim de que o filho consiga suportar este momento de espera/ausência, as mães realizam atitudes que o auxiliam nesse processo: "[...] se eu to fazendo alguma coisa que não tem como esperar, se eu não tenho como deixar [...] vou conversando com ela de onde eu tô e ela espera bem tranquila" (D10). Para Avellar (2004), é esse repertório sensorial que o bebê possui e que é construído no encontro com o corpo da mãe - os sons, o cheiro, o tato - que o instrumentalizam a suportar a ausência da mãe, sem prejuízos no continuar a ser do bebê.

\section{Comunicação mãe-bebê}

A comunicação entre a mãe e seu bebê destaca-se como uma das principais formas de interação entre a díade, e é um dos marcos norteadores para o desenvolvimento da relação que vai se estabelecendo entre os atores aqui envolvidos. Assim, cada parceiro da relação mãe-filho, de maneira consciente ou inconsciente, percebe e responde ao afeto do outro, existindo uma troca mútua e afetiva contínua (Spitz, 1965/1998).

Em momentos distintos do contato com as díades, seja durante a consulta de rotina no Programa da Criança ou na entrevista realizada com as mães, pode-se perceber a existência de uma comunicação entre a mãe e o bebê, vivenciada de modo afetivo entre ambos. Esses momentos destacaram-se pela intensa reciprocidade entre a díade, onde ambos respondiam um ao outro, e essa interação é, sobretudo, sustentada pela dupla (Seidl-de-Moura et al., 2004). Assim, as mães, na maioria das vezes, respondiam às vocalizações, aos gestos e às atitudes de seus bebês atribuindo um sentido para essas manifestações, comportamento este que evidencia, também, um saber sobre o filho. Os bebês, por sua vez, ao ouvirem a voz da mãe, sentirem o seu toque ou visualizarem a proximidade da mesma, acalmavam-se. Com isso, pode-se visualizar, de modo muito positivo para o desenvolvimento da criança e para a relação mãe-bebê, a presença dos indicadores 1 , 7 e 10 do instrumento IRDIs.

Para Spitz (1965/1998) a comunicação entre a díade no primeiro semestre de vida do bebê, e mesmo até completar o primeiro ano, pode ser verificada de forma não-verbal, ocorrendo a partir de formas de comportamento, que podem ser sinais posturais, assim como a emissão de sons. Corroborando com o autor citado, algumas das atitudes dos bebês são interpretadas pelas mães como sendo uma forma de chamar a sua atenção, as quais corresponderam, sem hesitar, aos "chamados" dos mesmos:

Ah, eu brinco com ela, eu digo "eu não quero", ela dá risada como quem diz assim "não quer mais em seguida vai vim me pega", ela já vem dando risada, já vem dando os braços, que ela sabe que a gente vai pega né. (D3)

Ele começa a gritar, ele grita, ele começa a conversa, ele chama a atenção assim, ou ele pega o brinquedinho dele e começa a bater no carrinho. (D7)

Da mesma forma que as mães atribuem um significado para as manifestações de seus bebês, também reconhecem certas atitudes como sendo o modo da criança estar tentando se comunicar. Para Seidl-de-Moura et al. (2004), a comunicação que existe na relação mãe-bebê pode ocorrer de formas diferentes: "através da troca de olhares, sorrisos, vocalizações, gestos, expressões faciais, tom de voz, brincadeiras e do choro" (Seidl-de-Moura et al., 2004, p. 297). Assim, quando questionadas se seus filhos já estavam tentando se comunicar, as mães responderam:

$E$ É ele ta começando a faze umas enrolada, e começo a faze assim com a cabeça não, não, não, não, não (mãe imita o gesto). (D4)

Ele conversa, dá umas enrolada, começa a conversa com ele, faz uma boquinha tão bonitinha, parece que já vai fala contigo. (D5)

Outro aspecto importante observado entre as díades refere-se às trocas de olhares presentes em vários momentos, acompanhadas de expressões dirigidas ao bebê num tom de voz diferenciado pela mãe, ou seja, no chamado manhês, confirmando a presença dos indicadores 2 e 5 do instrumento IRDIS. Para Pierotti et al. (2010), essa maneira particular e especial da mãe se comunicar com o filho é definida como "palavras cuja força libidinal marca a criança, palavras que dão sentido às suas manifestações, que serão utilizadas para expressar sua demanda e que, ao mesmo tempo, ajudam em seu movimento de diferenciação (Pierotti et al., 2010, p. 424).

Assim, expressões como: "é o zóinho da mãe", "tá babinha, "tá reinentinha" (D1); "tá fio, chega!" (D5); "A mãe ta aqui, não vai deixar que roubem você." (D6); podem exemplificar essa linguagem materna própria, observada nas díades do estudo e remetendo aos indicadores 2 e 9 do instrumento utilizado. Con- 
forme Flores et al. (2011, p. 147) "o manhês é visto como uma evidência de um vínculo entre mãe-bebê e como a origem dos mecanismos enunciativos necessários para a aquisição da linguagem".

[...] Eu to lavando louça e falando com ela "o que que foi, princesinha", essas coisas assim. Ela gosta, ela dá risada, sabe que é ela. Eu acho que ela já sabe quando a gente tá falando com ela, sabe, então todo mundo vem e dá risada, e fala que ela é princesa, né, e ela ri pra todo mundo, ela é bem risonha [falando em manhês com a filha]. (D8)

Em contrapartida às investidas das mães, os bebês correspondiam ao manhês geralmente sorrindo ou fazendo uma "gracinha" para a mãe, assim como pode ser percebido na fala da díade 8, remetendo-nos ao indicador 10 do instrumento IRDI. Nesse sentido, a partir da fala da díade acima e citando Pierotti et al. (2010, p. 431), o manhês se apresenta como "uma forma de comunicação que se caracteriza pelo investimento afetivo e costura os laços entre a mãe e o bebê, ao mesmo tempo em que vai se direcionando no sentido de facilitar sua separação".

\section{Amamentação}

A vivência da amamentação pode se constituir como significativa para a díade, na medida que, através do contato com o seio da mãe, se estabelece uma experiência de intimidade e união, propiciando, assim, a sensação de satisfação, prazer e completude para a dupla (Winnicott, 1987/1999). Além disso, o contato físico entre a mãe e o bebê, durante a amamentação, é fundamental para o aprendizado do bebê sobre a sua mãe (Cunnigham et al., 1991). Neste estudo, pode-se identificar que a amamentação se constituiu nesse momento lúdico e de interação, fortalecendo a aproximação entre mãe e bebê.

É, ela olha, as vez eu falo com ela, eu falo "não vo te dá a teta", ela já tá na teta e eu digo "não vo dâ", aí ela vê que é brincadeira, dá risada na teta mesmo, ela brinca, e fica, brincadeira. (D3)

Para Klein (1952/1991), esta gratificação está tão relacionada com o objeto que dá o alimento quanto com o próprio alimento. Bowlby (1969/2002) coloca que a presença da alimentação pode ajudar o bebê, porém o ato de sucção tem duas funções para ele uma nutritiva e outra não nutritiva - e que possivelmente a função não nutritiva tem uma importância maior. Isso porque o bebê passa mais tempo agarrado à mãe, abocanhando-lhe o seio, fazendo uma sucção não-nutritiva, do que ingerindo o alimento proveniente do seio materno. Conforme constatado por Klein (1952/1991), através de observações de bebês com apenas três semanas, estes interrompem as mamadas para brincar com o seio da mãe ou olhar para o rosto delas. Este aspecto pode ser observado nos relatos abaixo, onde, durante a amamentação, há momentos em que os bebês olham para a mãe, ouvem sua voz e respondem através de expressões faciais, numa espécie de conversa entre a díade:

Fica me olhando, e mama, e para, e dá risada, depois mama de volta. Mexe no peito assim, sabe. (D9)

[...] é uma criança calma, bem carinhosa - enquanto ela tá mamando ela faz carinho no peito, ou às vezes ela traz a mãozinha mais pro rosto. E eu também por acarinhar ela, e faço carinho nela e ela retribui, bem tranquila. Procuro conversar com ela também, tanto é que quando ela mordeu agora eu falei "agora tu vai parar de mamar e vai ficar de castigo, tu mordeu a mamãe", e ela dava risada [...]. (D10)

Assim, a amamentação, quando bem-sucedida, pode ser concebida como um elemento que facilita a função materna de se colocar em sintonia com o bebê, atendendo às suas necessidades primordiais. Dessa forma, contribui para que ele desenvolva a capacidade de estabelecer relações objetais; capacidade que se ampliará do objeto materno para o mundo exterior, norteando, inclusive, seus futuros relacionamentos (Costa \& Locatelli, 2008).

\section{A relação vista como gratificante pela mãe}

Através deste estudo pôde-se identificar que a relação mãe-bebê é vista como gratificante pelas mães, sendo que esta gratificação está relacionada à interação mãe-bebê que ocorre, como já apontado anteriormente, através da troca de olhares, comunicação, amamentação e contato físico (Kruel \& Souza, 2014; Scorsi \& Lyra, 2012; Vitorello, 2011). Isto pode ser observado nas falas a seguir:

Ah, eu acho maravilhoso! E converso com ela e de noite digo pra ela que ela tem que reza pra os anjinhos dela, converso, tudo [...] (D1)

Eu converso com ele, brinco com ele um pouco até [...] espero um minutinho e pego ele. Converso, brinco. Ele dá risada e começa a dá os bracinhos, aí eu pego ele (D11). 
De acordo com Bowlby (1988/1989) cada fase de interação inicia com um cumprimento inicial mútuo e continua com uma troca através de expressões faciais, na qual a criança se direciona para a mãe através dos movimentos de braços e pernas e termina com o bebê desejando um período de tempo, antes que a nova fase de interação comece. É importante considerar que a interação de uma criança e a sua interrupção tem a tendência de seguir o seu próprio ritmo. De acordo com o autor, uma mãe que é sensível, tende a regular e a modificar o seu comportamento de maneira que harmonize e se adapte com o de seu bebê.

Nos primeiros anos de vidas, as ações e experiências intencionais influenciam no desenvolvimento da personalidade do bebê. A presença da mãe e suas ações, por mais simples que sejam, agem como estímulo para as respostas do bebê. A busca pela comunicação com o parceiro é evidente e se torna mais dirigida conforme as semanas do bebê. Quando o bebê obtém êxito, seu prazer aumenta e ele repetirá as suas ações, assim como desistirá das ações em que não obtém o desejado (Spitz, 1965/1998). Uma mãe sensível que está atenta ao comportamento do bebê se comporta para satisfazer o filho. Assim, a mãe faz com que o filho se sinta alegre e, consequentemente, obtém a sua cooperação (Bowlby, 1988/1989). Dessa forma, uma atitude maternal e carinhosa que aprecia as atividades do filho facilita as ações deste (Spitz, 1965/1998).

As participantes do estudo remetem-se aos filhos de forma positiva e, assim, tornam o bebê atraente para o outro, principalmente pelas características que atribuem a ele, como criança tranquila, calma, sorridente e cooperativa, como pode ser percebido neste relato: "[...] é uma criança muito calma, é muito bom de cuida [...]" (D2). Neste contexto, é importante considerar os sentimentos da mãe para com o filho na relação da díade. Para Spitz (1965/1998), os sentimentos maternos criam na relação mãe-filho o que se denomina "Clima Emocional Favorável" (Spitz, 1965/1998). Segundo o autor, "o amor e a afeição pelo filho tornam-no um objeto de continuo interesse para a mãe e, além desse interesse persistente, ela oferece uma gama sempre renovada, rica e variada, todo um mundo de experiências vitais" (Spitz, 1965/1998, p. 99, 100). As experiências são interligadas e caracterizadas pelo afeto materno, sendo que a criança responde afetivamente a este afeto. Salienta-se que essas experiências são muito importantes para o desenvolvimento da criança e foram identificadas através das observações e falas das mães. Como exemplo, destaca-se a fala de uma participante: "Ontem ela passo o dia inteiro sorrindo pra mim. Ela acorda já rindo, ta de olho fechado, ta rindo." (D1). Na percepção de Bowlby (1988/1989), pais afetivos e um ambiente familiar estruturado, no qual a criança encontra proteção e conforto, possibilita que esta desenvolva um sentimento de segurança e confiança em relação a si mesma e aos que convivem com ela.

\section{CONSIDERAÇÕES FINAIS}

Este estudo se reveste de um significado muito importante, primeiramente por considerar a presença dos elementos subjetivos e constitutivos da vida psíquica no campo da saúde e, em especial, de uma instituição pública de saúde. Destaca-se que tais indicadores na saúde pública podem passar despercebidos pelos profissionais de saúde que, de maneira geral, estariam mais atentos aos aspectos nutritivos, crescimento e desenvolvimento físico. Assim, os resultados indicam, para além da importância deste momento na constituição psíquica da criança, o lugar especial e a atenção atribuída às mães nesse momento, saindo de uma perspectiva de naturalização da maternidade, para um olhar que busca no investimento e nos cuidados maternos a matriz para a constituição psíquica, destacando a sua importância nesse momento da vida do filho.

Assim, cuidar das relações iniciais e prestar atenção aos aspectos nem sempre evidentes que ali acontecem, certamente nos auxilia na detecção precoce de problemáticas na constituição psíquica dos bebês e nos possíveis riscos ao desenvolvimento na infância. Para que tal tarefa possa ser alcançada é fundamental a relação de confiança entre a equipe e as mães, onde os profissionais devem ter uma atitude que facilite a manifestação dos cuidados maternos, evitando interferir demasiadamente. Destacamos, ainda, a importância da combinação das técnicas utilizadas, a saber as observações realizadas em três momentos e a entrevista, pois a partir dessa combinação se pôde ter uma compreensão mais profunda da relação existente entre cada díade, complementando na entrevista aspectos observados nas consultas no Programa da Criança. A pesquisa finalizou com o procedimento de entrevista de devolução, momento no qual se pôde conversar abertamente com as mães, dando a elas o retorno so- 
bre o momento em que vivem com seus filhos e valorizando seu saber e as relações de cuidado ali identificadas pela equipe.

Estudos dessa natureza podem cumprir um papel preponderante nas ações dirigidas aos trabalhos na área materno-infantil, ampliando o olhar sobre o desenvolvimento infantil. Assim indica-se a relevância da inclusão dos Indicadores Clínicos de Risco ao Desenvolvimento Infantil nos serviços de atenção primária, tendo em vista que esse é o momento em que os profissionais de saúde, e em especial os profissionais da psicologia, tem acesso ao processo de constituição dos vínculos inicias. Saber compreendê-los e dar a eles a importância que lhes cabe é sem dúvida uma tarefa muito especial que nos é designada, e se coloca certamente como um grande desafio à nossa prática em saúde.

\section{REFERÊNCIAS}

Arpini, D. M., \& Santos, B. R. (2007). Programa da criança: Espaço de promoção de saúde e fortalecimento dos vínculos. Psicologia Argumentativa, 25, 155-164.

Avellar, L. Z. (2004). Jogando na análise de crianças: Intervir-interpretar na abordagem winnicottiana. São Paulo: Casa do Psicólogo.

Bardin, L. (1977). Análise de conteúdo $\left(70^{\mathrm{a}}\right.$ ed.) (L. A. Reto \& A. Pinheiro, Trans.). Lisboa: Edições.

Böing, E., \& Crepaldi, M. A. (2010). O Psicólogo na atenção básica: Uma incursão pelas políticas públicas de saúde Brasileiras1. Psicologia: ciência e profissão, 30(3), 634-649.

Borsa, J. C. (2007). Considerações acerca da relação mãebebê da gestação ao puerpério. Contemporânea - Psicanálise e Transdisciplinaridade, 2, 310-321.

Bowlby, J. (1989). Uma base segura: Aplicações clínicas da teoria do apego (S. M. Barros, Trans.). Porto Alegre: Artes Médicas. (Trabalho original publicado em 1988)

Bowlby, J. (2002). Apego e perda: Apego (Vol.1) (A. Cabral, Trans.). São Paulo: Martins Fontes. (Trabalho original publicado em 1969)

Costa, P. J., \& Locatelli, B., M. E. S. (2008). O processo de amamentação e suas implicações para a mãe e seu bebê. Mental, 6, 85-102.

Cunnigham, A. S., Jellife, D. B., \& Jellife, E. F. (1991). Breastfeeding and health in the 1980s: A global epidemiologic review. The Journal of Pediatrics, 118, 659666.

Flores, M. R., Beltrami, L., \& Souza, A. P. R. (2011). O manhês e suas implicações para a constituição do sujeito na linguagem. Distúrbios da Comunicação, 23, 143-152.
Gaskell, G. (2002). Entrevistas individuais e grupais. In W. Bauer \& G. Gaskell (Eds.). Pesquisa qualitativa com texto, imagem e som: Um manual prático (pp. 64-89). Petrópolis: Vozes.

Klein, M. (1991). Sobre a observação do comportamento de bebês. In M. Klein. Inveja e gratidão e outros trabalhos (pp. 119-148). Rio de Janeiro: Imago. (Trabalho original publicado em 1952).

Kruel, C. S., \& Souza, A. P. R. (2014). Aleitamento materno e cuidado: Uma proposta Winnicotiana. Distúrbios da Comunicação, 26(1), 176-186.

Kupfer, M. C. M., Jerusalinsky, A. N., Bernardino, L. M. F., Wanderley, D., Rocha, P. S. B., Molina, S. E., ... Lerner, R. (2009). Valor preditivo de indicadores clínicos de risco para o desenvolvimento infantil: Um estudo a partir da teoria psicanalítica. Lat. Am. Journal of Fund. Psychopath, 6, 48-68.

Pierotti, M. M. S., Levy, L., \& Zornig, S. A. (2010). O manhês: Costurando laços. Estilos da clínica, 15, 420433.

Scorsi, L., \& Lyra, M. C. D. P. (2012). O manhês e o desenvolvimento da comunicação adulto-bebê: Uma revisão da literatura com uma proposta de análise microgenética das trocas mãe-bebê. Interação em Psicologia, 16(2), 293-305.

Seidl-de-Moura, M. L., Ribas, A. F. P., Seabra, K. C., Pessoa, L. F., Nogueira, S. E., \& Ribas, R. C., Jr. (2004). Interações iniciais mãe-bebê. Psicologia: Reflexão e Crítica, 17, 295-302.

Spitz, R. A. (1998). O primeiro ano de vida (E. M. B. Rocha, Trans.). São Paulo: Martins Fontes. (Trabalho original publicado em 1965)

Vitorello, M. A. (2011). Família contemporânea e funções parentais: Há nela um ato de amor? Psicologia da Educação, 32, 7-24.

Winnicott, D. W. (1983). O ambiente e os processos de maturação: Estudos sobre a teoria do desenvolvimento emocional (I. C. S. Ortiz, Trans.). Porto Alegre: Artes Médicas. (Trabalho original publicado em 1982)

Winnicott, D. W. (1999). Os bebês e suas mães (J. L. Camargo, Trans.). São Paulo: Martins Fontes. (Trabalho original publicado em 1987)

Winnicott, D. W. (2000). Da pediatria à psicanálise: Obras escolhidas (D. Bogomoletz, Trans.). Rio de Janeiro: Imago. (Trabalho original publicado em 1958)

Recebido em: 25/06/2014 Última revisão em: 14/07/2014 Aceito em: 11/08/2014 
